\title{
PEMETAAN JENIS TANAH DI KELURAHAN ANDUONOHU KECAMATAN POASIA
}

\author{
Nursiani $^{1}$ \\ ${ }^{1}$ Alumni Pendidikaan Geografi Universitas Halu Oleo
}

\begin{abstract}
Abstrak: Penelitian ini berjudulPemetaan Jenis Tanah di Kelurahan Andounohu Kecamatan Poasia. Telah dilakukan pengukuran dengan menggunakan alat seismograph yang dilakukan oleh instansi BMKG Kota Kendari. Alat seismograph ini merupakan salah satu alat digunakan untuk mengetahui kondisi jenis tanah setempat. Jumlah titik pengukuran sebanyak 20 titik tersebar dari titik T 01 sampai T 20 berlokasi di Kecamatan Poasia. Lokasi Kecamatan Poasia merupakan wilayah dengan topografi kemiringan lereng $15-45 \%$ (curam/berbukit) dan merupakan Pengembangan pusat-pusat kegiatan skala besar baik yang telah berkembang di Pusat Kota, Pusat Pendidikan Tinggi dan Pemerintahan, maupun pusat-pusat kegiatan primer baru yang akan dikembangkan yaitu kawasan pelabuhan. Dengan banyaknya infrastr uktur dan topografi penting penelitian dimaksudkan untuk merevisi informasi jenis tanah yang telah ada. Informasi jenis tanah yang diperoleh dari data BMKG ini selanjutnya menganalisis dan memetakan wilayah/yang di jadikan objek penelitian melalui salah satu aplikasi dari Sistem Informasi Geografis (SIG). Data yang diperoleh dari pengukuran ini berupa nilai frekuensi dan kemudian dikerelasikan dengan jenis tanah dengan merujuk pada Buletin BMKG. Berdasarkan hasil yang diperoleh memperlihatkan bahwa Kecamatan Poasia berdasarkan persentase hasil pengukuran lapangan diperoleh $55 \%$ terdiri atas jenis tanah alluvial berlumpur, $15 \%$ terdiri atas alluvial dengan jenis loam dan $30 \%$ terdiri atas gravel dan sandy gravel. Dapat dikatakan bahwa dominasi tanah alluvial berlumpur di Kecamatan Poasia. Ini disebabkan kecamatan ini terletak dekat dengan daerah aliran sungai Wanggu.
\end{abstract}

\section{Kata Kunci: Topografi, Jenis Tanah, System Informasi Geografis (SIG) Kecamatan Poasia}




\title{
MAPPING OF SOIL TYPES IN ANDOUNOHU SUBDISTRICT, POASIA DISTRICT
}

\author{
Nursiani $^{1}$ \\ ${ }^{1}$ Geography Educational Alumni Halu Oleo University
}

\begin{abstract}
This research entitled Mapping of Soil Types in Andounohu Subdistrict, Poasia District. Measurements have been made using seismographs conducted by BMKG agencies in Kendari City. This seismograph tool is one of the tools to determine the condition of local soil types. The points of measuring points as many as 20 points spread from points T 01 to T 20 located in Poasia District. The location of Poasia Subdistrict is an area with slope topography of 15 - 45\% (steep / hilly) and is a development of the Center for Higher Education and Government, which is developed in the City Center, as well as new primary activity centers that will develop namely the port area. By using the infrastructure and topography needed to provide information about existing land. Information from the land obtained from BMKG data then maps and maps the area that is made of research in one of the applications of the Geographic Information System (GIS). The data obtained from this measurement is frequency and then correlated with the soil with the BMKG Bulletin. Based on the results obtained from Tanah Mawu Subdistrict, 15\% consists of all types of species and 30\% consists of gravel and gravel sand. It can be said that this is the dominance of muddy alluvial soils in the District of Poasia. The Wanggu river basin.
\end{abstract}

\section{Keywords: Topography, Land Type, Geographic Information System (GIS) in the Subdistrict of Poasia}

\section{PENDAHULUAN}

Kondisi topografi pada daerah Anduonohu di dominasi oleh tingkat kemiringan lereng antara $0-$ 3\% dengan kategori datar yang tersebar hampir seluruh wilayah pada daerah Anduonohu, dengan luas 2.169,3 Ha. Lahan dengan kemiringan lereng $8-15 \%$ dengan kategori landai pada daerah Anduonohu seluas 486,03 Ha yang terdapat pada Kelurahan Anduonohu, Kelurahan Rahandouna, Kelurahan Makoau dan Kelurahan Lepo-Lepo. Kemiringan lahan 15 25\% pada daerah Anduonohu dengan luas 155,85 Ha yang terdapat pada Kelurahan Anduonohu dan lahan dengan tingkat kemiringan lereng 25 -
40\% dan lebih besar dari $40 \%$ terdapat pada Kelurahan Anduonohu dengan luas wilayah 103,90 $\mathrm{Ha}$ dan kemiringan lereng lebih dari 40\% terdapat pada Kelurahan Anduonuhu (Sulkarnain, 2008).

Perbedaan jenis tanah antara satu daerah menjelaskan ketahanan wilayahnya. Sifat fisik tanah sendiri yang merupakan faktor penentu. Pemahaman terhadap karakteristik jenis tanah ini merupakan salah satu upaya untuk memperkecil dampak kerugian diakibatkan bencana alam seperti tanah longsor, guncangan akibat gempa bumi, guncangan akibat getaran bunyi kendaraan dan lain-lain. Beberapa kasus yang tidak memperhitungkan faktor jenis tanah 
setempat, sehingga seringkali di Kecamatan Poasia ini mengalami kerugian kerusakan infrastruktur baik material maupun nonmaterial.

Kawasan Anduonohu yang terbagi kedalam 5 (lima) kelas lereng yaitu $0-3 \%, 3-15 \%, 15-25 \%$, $25-40 \%$ dan $40 \mathrm{ke}$ atas, dengan ketinggian dari permukaan laut (dpl) antara 0 - 500 Meter dpl. Dari data tersebut dapat dilihat bahwa perbedaan topografi BWK V Kawasan Anduonohu mencerminkan variasi bentuk permukaan, dari yang datar permukaan sampai berbukit, akan memerlukan penanganan berbeda yang harus disesuaikan dengan kondisi topografi dan kemiringan lereng pada masing-masing wilayah. Lahan yang memiliki kemiringan lereng antara 25 - $40 \%$ keatas merupakan lahan berbukit yang sangat berpotensi untuk terjadinya erosi, sliding, longsor maupun bentuk gerakan permukaan tanah lainnya untuk itu maka perlu mendapatkan perhatian khusus dalam pemanfaatan lahannya, sedangkan untuk lahan datar dalam pemanfaatan ruangnya perlu memperhatikan pola jaringan drainase dan resiko bahaya banjir yang dapat timbul (Gutenberg, 1954 dalam Tommy A.,2012).

Jenis tanah antara daerah yang satu dengan daerah yang lain memiliki perbedaan. Perbendaan jenis tanah disebabkan oleh perbedaan batuan induk, curah hujan, intensitas penyinaran matahari, relief, dan tumbuhan penutup tanah (Agus, 2010).

Daerah-daerah yang memiliki indeks kerentanan seismik tanah yang tinggi ternyata memiliki resiko yang tinggi terhadap kerusakan akibat gempa bumi.Hasil dari pengukuran alat TDL 303S ini menampilkan nilai frekuensi alamiah (fo) untuk menunjukkan jenis dan karakterisktik batuan tersebut (Daryono : 2009).
Salah satu model informasi yang berhubungan dengan data spasial (keruangan) mengenai daerah-daerah di permukaan Bumi adalah Sistem Informasi Geografi (SIG). Pengertian SIG adalah suatu sistem yang menekankan pada informasi mengenai daerah-daerah berserta keterangan (atribut) yang terdapat pada daerahdaerah di permukaan Bumi. Dengan demikian, sistem informasi geografi tidak hanya befungsi sebagai "alat pembuat peta", tetapi lebih jauh dari itu. Sistem informasi geografi mampu menghasilkan suatu sistem informasi yang aplikatif, yang dapat digunakan oleh perencanaan atau oleh pengambil keputusan untuk kepentingan pengolahan sumber daya yang ada di suatu wilayah. Perkembangan informasi akan data keruangan di era kemajuan ilmu pengetahuan dan teknologi ini semakin dibutuhkan karena membutuhkan data yang akurat, praktis, dan efisien. Dengan demikian, munculah yang dinamakan Sistem Informasi Geografi (SIG). Istilah Sistem Informasi Geografi (SIG) banyak digunakan dan tidak asing lagi di kalangan ahli geografi (geograf), yaitu proses pembuatan peta digital dengan menggunakan komputer. Namun, pada intinya, SIG tidak hanya digunakan untuk membuat peta saja, melainkan lebih dari itu, SIG digunakan dalam pengolahan data keruangan dengan menggunakan komputer.

SIG dapat merepresentasikan realworld (dunia nyata) di atas monitor komputer sebagaimana lembaran peta dapat merepresentasikan dunia nyata di atas kertas. Namun SIG memiliki kekuatan lebih dan fleksibilitas dari pada lembaran peta kertas. Peta merupakan representasi grafis dari dunia nyata, objek-objek yang direpresentasikan di 
atas peta disebut unsur peta atau map features (contohnya adalah sungai, kebun, jalan, dan lain-lain). Karena peta mengorganisasikan unsur-unsur berdasarkan lokasi-lokasinya, peta sangat baik dalam memperlihatkan hubungan atau relasi yang dimiliki oleh unsur-unsurnya. Kemudian SIG membentuk dan menyimpannya di dalam tabel-tabel (relasional). Setelah itu, SIG menghubungkan unsur-unsur di atas dengan tabel-tabel yang bersangkutan. Dengan demikian, atribut-atribut ini dapat diakses melalui lokasi-lokasi unsur-unsur peta, dan sebaliknya unsur-unsur peta juga dapat diakses melalui atributatributnya. Karena itu, unsur-unsur tersebut dapat dicari dan ditemukan berdasarkan atribut-atributnya. SIG menghubungkan sekumpulan unsurunsur peta dengan atribut-atributnya di dalam satuan-satuan yang disebut layer. Contoh-contoh layer seperti bangunan, sungai, jalan, batas-batas administrasi, perkebunan, dan hutan. Kumpulan-kumpulan dari layer-layer ini akan membentuk basisdata SIG. Dengan demikian, perancangan basis data merupakan hal yang esensial di dalam SIG. rancangan basisdata akan menentukan efektifitas dan efisiensi proses-proses masukan, pengelolaan, dan keluaran SIG (Eddy Prahasta, 2002).

Kemampuan SIG dapat juga dikenali dari fungsi-fungsi analisis yang dapat dilakukannya. Secara umum terdapat dua jenis fungsi analisis, yaitu fungsi analisis spasial dan fungsi analisis atribut. Fungsi analisis atribut terdiri dari operasi dasar basisdata yang mencakup createdatabase, drop database, create table, drop table, record dan insert, field, seek, find, search, retrieve, edit, update, delete, zap, pack, memmbuat indeks untuk setiap tabel basisdata, dan perluasan operasi basisdata yang mencakup export dan import, structured query language, dan operasi-operasi atau fungsi analisis lain yang sudah rutin digunakan di dalam sistem basisdata. Fungsi analisis spasial terdiri dari reclassify, overlay, dan buffering (Eddy Prahasta, 2002).

Walaupun produk SIG paling sering disajikan dalam bentuk peta, kekuatan SIG yang sebenarnya terletak pada kemampuannya dalam melakukan analisis. SIG dapat mengolah dan mengelola data dengan volume yang besar. Dengan demikian, pengetahuan mengenai bagaimana cara mengekstrak data tersebut dan bagaimana menggunakannya merupakan kunci analisis di dalam SIG. Salah satu fungsi tools SIG yang paling powerful dan mendasar adalah integrasi data dengan cara baru. Salah satu contohnya adalah overlay, yang memadukan layers data yang berbeda. SIG juga dapat mengintegrasikan data secara matematis dengan melakukan operasi-operasi terhadap atribut-atribut tertentu dari datanya (Eddy Prahasta, 2002).

ArcGISmerupakan salah satu perangkat lunak desktop Sistem Informasi Geografis dan pemetaan yang telah dikembangkan oleh ESRI (Environmental System Research Institute, Inc). Dengan ArcGIS, pengguna dapat memiliki kemampuankemampuan untuk melakukan visualisasi, mengexplore, menjawab query (baik basis data spasial maupun non-spasial), menganalisis data secara geografis, dan sebagainya. Kemampuan perangkat SIG ArcGISsecara umum dapat dijabarkan sebagai berikut (Eddy Prahasta, 2002): 
1. Pertukaran data : membaca dan menuliskan data dari dan ke dalam format perangkat lunak SIG lainnya.

2. Melakukan analisis statistik dan operasi-operasi matematis.

3. Menampilkan informasi (basisdata) spasial maupun atribut.

4. Menjawab query spasial maupun atribut.

5. Melakukan fungsi-fungsi dasar SIG.

6. Membuat peta tematik.

7. Meng-customize aplikasi dengan menggunakan bahasa skrip.

8. Melakukan fungsi-fungsi SIG khusus lainnya (dengan menggunakan extension yang ditujukan untuk mendukung penggunaan perangkat lunak SIG ArcGIS.

Sebelum berkembangnya teknologi komputer, data wilayah umumnya tersimpan dalam bentuk tabel, grafik, peta, foto udara, atau deskripsi. Analisis, manipulasi, dan presentasi data dilakukan secara manual sehingga banyak membutuhkan tenaga dan waktu. Dengan mempergunakan komputer, penyimpanan dan pengelolaan data dapat dilakukan lebih cepat walaupun tidak berarti cara manual ditinggalkan sama sekali. Oleh karena komputer hanya dapat bekerja, menyimpan dan memroses data digital, maka di dalam komputerisasi data geografi perlu dilakukan penyesuaian. Pada perkembangannya, pengelolaan data geografi mempergunakan komputer ini lebih dikenal dengan Geographic Information System (GIS). GIS adalah sistem informasi yang mempunyai referensi geografi untuk spesifikasi, perolehan, penyimpanan, mendapatkan kembali, dan manipulasi data (Prapto Suharsono, 1989: 1-2).
Data yang menjadi bahan baku dalam proses GIS adalah data spasial/geodata (data yang mengacu pada lokasi geografi), akan diproses menjadi informasi spasial/ geoinformasi yang salah satu bentuk penyajiannya adalah peta (maps). Data yang akan dikelola GIS terdiri dari dua kelompok, yaitu data grafis dan data non-grafis/diskriptif/atribut. Data grafis tersusun dalam bentuk titik (dot), garis (line), atau area/poligon (area), sedangkan data diskriptif dapat berupa data kwalitatif (seperti nama, jenis, tipe, dan sebagainya) atau data kwantitatif (seperti angka, satuan, besaran, jumlah, tingkatan, kelas, interval, dan sebagainya) yang mempunyai hubungan satu-satu dengan data grafisnya. Poligonpoligon yang menjadi data grafis ini dikenal sebagai satuan pemetaan (mapping unit) (Paul Suharto, 1989: 59).

Kemajuan teknologi terutama teknologi komputer, telah membuat GIS berkembang dalam bentuk yang sekarang ini. Pengembangan teknologi dalam pengadaan data spasial dan teknik pengolahan dan pengelolaan data seperti penentuan posisi dengan satelit, penginderaan jauh, pemetaan digital, analisa spasial, CAD/CAM (komputerisasi desain dan proses produksi), mempunyai kontribusi dalam membuat GIS berpenampilan tinggi hingga dapat memenuhi kebutuhan dunia modern (Paul Suharto, 1989: 59-60).

\section{METODE PENELITIAN}

\section{Jenis Penelitian}

Penelitian ini termasuk dalam jenis penelitian eksperimen. Dalam penelitian ini pada penyediaan informasi berupa sekunder yaitu pengambilan data pada kantor BMKG 
untuk lokasi titik pengukuran di Wilayah Kelurahan Anduonohu Kecamatan Poasia.

\begin{abstract}
Survei Lokasi Penelitian
Pada penelitian ini menggunakan metode pengumpulan data sekunder. Metode pengumpulan data sekunder dalam penelitian ini adalah studi pustaka dan survei instansi. Kebutuhan data tersebut tersedia dalam dokumen rencana serta informasi jenis tanah.
\end{abstract}

\section{Alat dan Bahan Penelitian}

Tabel 2.1. Alat dan Bahan Dalam Penelitian

\begin{tabular}{cll}
\hline No & \multicolumn{1}{c}{ Alat dan Bahan } & \multicolumn{1}{c}{ Fungsi } \\
\hline 1 & GPS & Untuk menentukan posisi koordinat pengukuran. \\
\hline 2 & Kamera & Sebagai dokumentasi pengambilan gambar \\
\hline 3 & $\begin{array}{l}\text { Laptop Dengan } \\
\text { Aplikasi ArcGis }\end{array}$ & Untuk mengolah data analog ke data digital \\
\hline 4 & $\begin{array}{l}\text { Alat - Alat Penunjang } \\
\text { Lainya }\end{array}$ & Untuk membantu kelangsungan pengambilan data. \\
\hline 5 & ArcGis 10.2 & $\begin{array}{l}\text { Sebagai Program untuk mengolah dan } \\
\text { menginterprestasi data }\end{array}$ \\
\hline 6 & GoogleEarth pro & Untuk memplot wilayah titik koordinat \\
\hline 7 & GlobalMapper & Untuk overlay (gambar tumpang susun) \\
\hline 8 & Surfer & Untuk peta sebaran jenis tanah \\
\hline 9 & Alat - Alat Tulis & $\begin{array}{l}\text { Pencatat/observasi data sekunder sesuai kebutuhan } \\
\text { di instansi yang terkait dengan penelitian }\end{array}$ \\
\hline & $\quad$ Sumber: Hasil observasi dan wawancara di BMKG 2018
\end{tabular}

\section{Prosedur Penelitian}

Prosedur kerja yang akan di lakukan dalam penelitian ini yaitu menggunakan data skunder berupa penyusun peta wilayah berdasarkan jenis tanah.

\section{Teknik Pengumpulan dan Analisis Data}

Data yang berhasil dikumpulkan dalam penelitian ini adalah data yang diperoleh dari BMKG. Menurut hasil observasi dengan tenaga ahli BMKG perolehan data tersebut berasal dari hasil pengukuran alat TDL 303S yang dapat merekam getaran tanah dan mengkonversinya pada jenis tanah.
Analisis data pembuatan peta sebaran jenis tanah adalah sebagai berikut :

a. Menganalisis data yang diperoleh dari instansi BMKG berupa data mentah (.geops)

b. Cek data setiap letak titik pengukuran

c. Data tersebut berisi data koordinat titik pengukuran dan jenis tanah yang telah disesuaikan

d. Data yang telah diperoleh kemudian dibuatkan peta sebaran titik pengukuran dan peta jenis tanah.

e. Pembuatan peta yang berisi beberapa informasi dibagi menjadi 3 tahapan yaitu: 
1) Memasukan data (input)

2) Prosesing Data

a) Pembuatan Peta Penentuan Lokasi

b) Pembuatan Peta Daerah Penelitian

c) Pembuatan sebaran jenis tanah

d) Penyajian Data

\section{GAMBARAN UMUM PENELITIAN}

\section{Letak Geografis dan Batas Wilayah}

Kota kendari terbentuk dengan Undang-Undang Republik Indonesia No.6 Tahun 1995 yang disahkan pada tanggal 3 Agustus 1995 dengan statusnya Kotamadya Daerah TK.II Kendari. Kemudian dengan keluarnya Undang-Undang No. 22 Tahun 1999 tentang Pemerintahan Daerah Tingkat II Kendari berubah menjadi Kota Kendari. Kota Kendari memiliki posisi strategis karena fungsi dan perananya sebagai ibu kota Propinsi Sulawesi Tenggara yang juga merupakan pusat aktifitas ekonomi dan pemerintahan serta pintu gerbang Propinsi Sulawesi Tenggara. Pembagian wilayah administrasi Kota Kendari mliputi beberapa Kecamatan, salah satunya yaitu Kecamatan Poasia.

Wilayah Kecamatan Poasia terdiri dari 4 kelurahan yakni Kelurahan Anduonohu, Kelurahan Rahandouna, Kelurahan Anggoeya dan Kelurahan Matabubu. Kecamatan Poasia memiliki luas wilayah 5.250 $\mathrm{km}^{2}$ terdiri dari tanah pertanian 2.365 $\mathrm{Ha}$, sebanyak $941 \mathrm{Ha}$ merupakan hutan dan sisanya digunakan sebagai pemukiman, sarana sosial dan sebagainya.Wilayah Kecamatan Poasia membujur dari arah barat ke timur dan melintang dari utara keselatan dengan batas-batas sebagai berikut:

Sebelah Utara berbatasan dengan Teluk Kendari
$>$ Sebelah Timur berbatasan dengan Kecamatan Abeli

$>$ Sebelah Selatan berbatasan dengan Kab. Konawe Selatan

Sebelah Barat berbatasan dengan Kecamatan Kambu

\section{Topografi}

Berdasarkan interpretasi pada peta topografi yang ada diperoleh gambaran topografi wilayah perkecamatanya:

1. Wilayah bagian timur didominasi oleh daerah bergelombang sampai berbukit dengan kemiringan lereng $15-45 \%$. Daerahnya meliputi Kecamatan Abeli, Poasia, dan Kecamatan Kendari.

2. Wilayah bagian tengah didominasi daerah datar dan bergelombang dengan kemiringan lereng antara $0-20 \%$ yang meliputi wilayah Kecamatan Mandonga, Wua-Wua dan Kecamatan Powatu.

3. Wilayah bagian selatan didominasi daerah bergelombang yaitu Kecamatan Baruga.

Jadi dapat ditafsirkan bahwa topografi Kecamatan Poasia bergelombang dan berbukit. Dengan keadaan topografi yang cukup curam ini ditambah lagi pembangunan yang terdapat diwilayah tersebut menjadikan Kecamatan Poasia menjadi catatan beberapa kali ketika terjadi gempa yang di catat oleh BMKG dengan kerusakan bangunan yang parah.

\section{KeadaanTanah dan Iklim}

Tanah merupakan factor yang sangat penting bagi kehidupan karena tanah merupakan tempat kita tinggal dan berpijak. . Di Kecamatan Poasia berdasarkan kondisi tanah pada umumnya termaksud jenis pedsolik merah kuning dan tanah endapan 
(alluvial) dengan tingkat kesuburan sedang serta $\mathrm{pH}$ berkisar antara 5,56,5. Bentuk permukaan tanah pada umumnya landai sampai bergelombang dan ketinggian tanah diatas 0 sampai dengan $7 \mathrm{M}$ di atas permukaan laut. TopografiwilayahKecamatan Poasia umumnyadatarsampaiberombakdengan luas60\%,sedangkansisanya berombaksampaiberbukit $25 \%$ danberbukitsampai bergunung $15 \%$ darikeseluruhanluaswilayahKeca matanPoasia. Wilayahini terletakpada ketinggian0-

2000Mdariataspermukaanlautdimana kondisiini sangatlah rawan bagi yang memiliki kediaman/rumah di sekitaran tempat tinggal tersebut.

WilayahKecamatan Poasia mempunyai2tipeiklim, yaituiklimCdan iklimD, dimanauntukiklimC memilikicurahhujanrata-rata $1.500 \mathrm{~mm}$ dengan

jumlahbulanbasah8bulan/tahun,sedang kaniklimDmemilikijumlahbulan basah5-

6bulan/tahun.Wilayahinitermaksuddae rahtropisdengansuhurata-rata2 $2^{0} \mathrm{C}$ $33^{0} \mathrm{C}$ $33 \mathrm{C}$.

\section{Geologi}

Secara umum, keadaan tanah (soil) Kecamatan Poasia ini terdiri dari tanah liat bercampur pasir halus dan berbatu. Diperkirakan sebagai jenis aluvium berwarna coklat keputihputihan dan ditutupi batuan pratersier terdiri dari batuan batu lempung bergelimer, batu pasir dan kwarsa. Dibagian pantai batuan pratersier tersebut ditutupi batuan terumbu gamping. Keadaan batuan yang demikian umumnya tidak meluas air atau kedap air.
Adapun persebaran dan jenis batuan yang terdapat di Kota Kendari adalah sebagai berikut :

1. Endapan eluvium Pasir, lempung dan lumpur, tersebar dipesisir pantai Teluk Kendari dan disekitar sungai-sungai yang mengalir di Kota Kendari.

2. Batu Gamping Oral dan Batu Pasir yang tersebar di Pulau Bungkutoko, pesisir pantai Kelurahan Purirano dan Kelurahan Mata, serta Kecamatan Mandonga kearah Barat Laut, yang dibatasi Jalan R. Soeprapto Jalan Imam Bonjol dan batas antara Kota Kendari dengan Kecamatan Sampara.

3. Konglomerat dan Batu Pasir , tersebar disepanjang kiri kanan jalan poros antara Kota Lama dengan Tugu Simpang tiga Mandonga, bagian tengah Kecamatan Mandonga dan Bagian Barat Kecamatan Baruga serta bagian tengah Kecamatan Poasia sampai kearah selatan, yaitu kawasan rencana kompleks perkantoran $1.000 \mathrm{Ha}$ kearah pegunungan Nanga-Nanga.

4. Filit, Batu Sabak, Batu Pasir Malik Kuarsa Kalsiulit, Napai, Batu Lumpur dan Kalkarenit Lempung, tersebar di arah tenggara Kecamatan Poasia tepatnya Kelurahan Talia, Kelurahan Abeli, Kelurahan Anggalomelai, Kelurahan Tobimeita, Kelurahan Benuanirae dan Kelurahan Anggoeya.

5. Konglomerat Batu Pasir, Batu Lanau dan Batu Lempung, tersebar di Kecamatan Poasia bagian timur yaitu di Keluahan Petoaha, Kelurahan Sambuli dan Kelurahan Nambo serta sebagian Kelurahan Tondonggeu.

$$
\text { Adapun dari segi }
$$

geologisnya, Kota Kendari secara 
makro terdiri dari beberapa sistem lahan dan litologi yaitu Punggung metamorfik terorientasi terjal, Dataran bergelombang yang berbukit kecil di atas napal dan batu gamping, Dataran gabungan endapan muara dan sungai, Dataran berbukit kecil di atas batuan metamorfik campuran, Punggung bukit sedimen asimetrik tak terorientasi, Kipas aluvial non vulkanik yang melerang landai, Gunung karstik di atas marmer, Dataran lumpur antar pasang surut di bawah halofit, Dataran sedimen campuran yang berombak sampai bergelombang, Bukit karst di atas marmer dan batu gamping, Kipas aluvial non vulkanik yang melereng sedang dan Dataran berbukit kecil di atas batu sedimen campuran.

Berdasarkan peta Hazard Gempa Indonesia 2010 yang telah disusun oleh Badan Penelitian dan Pengembangan,

Kementerian Pekerjaan Umum 2010, maka Kota Kendari termasuk daerah dengankerawanan gempa tingkat sedang, dengan nilai spektrum respon percepatan 1 detik di batuan dasar $S_{B}$ untuk probabilitas terlampaui $10 \%$ dalam 50 tahun (redaman 5\%) adalah $0,15-0,2 \mathrm{~g}$.

\section{Tata Ruang Wilayah}

Pengembangan struktur ruang Kota Kendari pada 20 tahun mendatang yang didasarkan pada pertimbangan, bahwa Pengembangan pusat-pusat kegiatan skala besar baik yang telah berkembang di Pusat Kota, Pusat Pendidikan Tinggi dan Pemerintahan, maupun pusat-pusat kegiatan primer baru yang akan dikembangkan yaitu kawasan pelabuhan, kawasan industri dan kawasan CBD ("Central Bussines District"). Pengembangan pusat primer akan menjadi magnet pertumbuhan kota yang tersebar di Kota Kendari:

a. Pengembangan Pusat Kota dan CBD.

Pusat Kota Kendari yang akan dikembangkan sebagai pusat pemerintahan, permukiman, perdagangan dan jasa akan menyatu dengan kawasan CBD sehingga akan menjadi pusat kegiatan perkotaan skala besar.

b. Perkembangan Kawaan Pendidikan Tinggi dan Pusat Pemerintahan Provinsi.

Kawasan Pendidikan Tinggi dan Pemerintahan Provinsi akan berfungsi sebagai simpul primer di selatan Kota Kendari dan berkembang sebagai pusat permukiman perkotaan baru dalam skala besar.

c. Pengembangan Kawasan Pelabuhan Bungkutoko dan Kawasan Industri.

Kawasan Pulau Bungkutoko dikembangkan sebagai kawasan pelabuhan barang dan penumpang skala regional dan internasional. Fungsi tersebut menjadikan Pulau Bungkutoko menjadi pusat primer di kawasan timur Kota Kendari.

d. Pengembangan Kota Lama

Kota lama memiliki nilai historis bagi Kota Kendari, fungsinya tetap dipertahankan dan dijaga dari kemungkinan tergradasinya fungsi ekonomi sebagai akibat pengembangan kawasan pelabuhan di Pulau Bungkutoko. Dengan tetap mempertahankan fungsinya, Kota lama tetap akan menjadi simpul pusat kegiatan penting di kawasan timur Kota Kendari sebelah utara.

e. Kawasan Terminal

Kawasan terminal yang berada di persimpangan Jalur Regional, akan menjadi simpul pertumbuhan baru di Selatan Kota Kendari. Lokasinya 
yang cukup strategis, dengan dukungan aksesibilitas kawasan terminal akan menjadi pilihan potensial bagi pengembangan kawasan permukiman baru di bagian selatan kota.

Untuk melihat Potensi

Pengembangan Wilayah menurut Peta Rencana Pola Pemanfaatan Kota Kendari 2009 -2029 yang dibuat oleh Pemerintah Kota Kendari terdapat 28 Zonasi kegiatan, sedangkan yang termasuk kedalam kawasan budi daya sebanyak 20 zonasi yaitu; hutan produksi terbatas, industri, industri dan pergudangan, pariwisata, pertahanan dan keamanan, komersial, campuran, pemerintahan, pendidikan tinggi, pertanian lahan basah, pertanian lahan kering, pemukiman, fasilitas pelayanan, pelabuhan, industri tidak mengganggu, terminal, rumah sakit, kepentingan pariwisata dan nelayan dan kepentingan pelabuhan.

\section{Sosial dan Budaya}

Dalam pelaksanaan
pembangunan disegala bidang,
pemerintah telah berupaya secara maksimal agar tercipta kesejahteraan masyarakat yang salah satunya adalah bidang sosial budaya. Usaha tersebut antara lain melalui kegiatan dibidang pendidikan, kesehatan, keluarga berencana, agama, keamanan dan ketertiban masyarakat serta bidang sosial lainnya. Pembangunan di bidang sosial lainnya di Kota Kendari diarahkan untuk terwujudnya kehidupan dan penghidupan sosial, baik dari segi material maupun dari segi spiritual, utamanya dapat mengatasi masalah kesejahteraan sosial seperti kemiskinan, keterbelakangan, keterlantaran, kerawanan, ketentraman sosial dan bencana alam.

Dasar penyediaan sarana pendidikan adalah untuk melayani setiap unit administrasi pemerintahan baik yang informal (RT, RW) maupun yang formal (Kelurahan, Kecamatan), dan bukan didasarkan semata-mata pada jumlah penduduk yang akan dilayani oleh sarana tersebut. Dasar penyediaan sarana pendidikan ini juga mempertimbangkan pendekatan desain keruangan unit-unit atau kelompok lingkungan yang ada.

\section{HASIL PENELITIAN DAN PEMBAHASAN}

\section{Data Hasil Pengukuran}

Berdasarkan pada observasi dan hasil konsultatif dari seorang ahli/spesialis dari pihak BMKG yang menangani informasi yang diperlukan, diperoleh data informasi jenis tanah yang selanjutnya dijadikan dasar pembuatan peta jenis tanah yang diperoleh dari informasi nilai jenis tanah atau $\left(\mathrm{f}_{0}\right)$ yang diperoleh dari hasil pengukuran lapangan yang dilakukan pihak BMKG Kota Kendari.

Namun pada pengukuran atau hasil pengambilan data, data tersebut sudah berisi informasi yang diperlukan peneliti yaitu informasi nilai koordinat dan jenis tanah $\left(\mathrm{f}_{0}\right)$. Menurut SESAME European Research Project (2004) mengenai proses pengambilan/pengukuran rekaman getaran tanah dalam hal penentuan nilai dari jenis tanahnya. Merujuk pada penentuan jenis tanah yang didasarkan pada nilai $\left(\mathrm{f}_{0}\right)$ dapat dilihat pada tabel di bawah ini. 
Tabel 4.1.

Tabel Kalisifikasi Tanah Berdasarkan Nilai $f_{0}$ Oleh Kanai (Dikutip dari Buletin Meteorologi dan Geofisika No.4, 1998)

\begin{tabular}{|c|c|c|c|}
\hline $\begin{array}{l}\text { Klasifikasi } \\
\text { Tanah }\end{array}$ & $f_{0}$ & Jenis Tanah & Deskripsi \\
\hline \multirow{2}{*}{ TIPE IV } & \multirow{2}{*}{$>4$} & $\begin{array}{l}\text { Batuan tersier atau lebih } \\
\text { tua. Terdiri dari batuan } \\
\text { Hardsandy, gravel, dll }\end{array}$ & $\begin{array}{l}\text { Ketebalan sedimen } \\
\text { Permukaannya sangat tipis, } \\
\text { didominasi oleh } \\
\text { batuan keras }\end{array}$ \\
\hline & & $\begin{array}{l}\text { Batuan alluvial, dengan } \\
\text { ketebalan 5m. Terdiri } \\
\text { darisandy-gravel, sandy } \\
\text { hard clay, loam, dll }\end{array}$ & $\begin{array}{l}\text { Ketebalan sedmien } \\
\text { Permukaannya masuk } \\
\text { dalam kategori menengah } \\
\text { 5-10 meter }\end{array}$ \\
\hline TIPE III & $2,5-4$ & $\begin{array}{l}\text { Batuan alluvial, dengan } \\
\text { ketebalan }>5 \mathrm{~m} \text {.Terdiri } \\
\text { darisandy-gravel, sandy } \\
\text { hard clay, loam, dll. }\end{array}$ & $\begin{array}{l}\text { Ketebalan sedimen } \\
\text { Permukaan masuk dalam } \\
\text { kategori tebal, } \\
\text { sekitar } 10-30 \text { meter }\end{array}$ \\
\hline TIPE II & $0,5-2,5$ & $\begin{array}{l}\text { alluvial, yang terbentuk } \\
\text { dari sedimentasi delta, }\end{array}$ & Ketebalan sedimen \\
\hline TIPE I & $0,15-0,5$ & $\begin{array}{l}\text { Alluvial terdiri dari } \\
\text { batuan gravel }\end{array}$ & 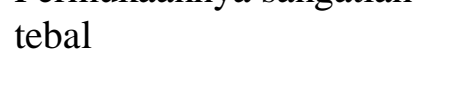 \\
\hline
\end{tabular}

Sumber: Hasil observasi dan wawancara di BMKG 2018

Selanjutnya memasukan nilai jenis tanah yang diperoleh dari pengukuran lapangan. Untuk melihat hasil pengukuran lapangan yang didasarkan pada Kalisifikasi Tanah
Berdasarkan Nilai $f_{0}$ yang Dikutip dari Buletin Meteorologi dan Geofisika No.4, 1998 dapat dilihat pada tabel di bawah ini.

Tabel 4.2. Kalisifikasi Tanah Berdasarkan Nilai $f_{0}$ Pengukuran

\begin{tabular}{|c|c|c|c|c|}
\hline \multirow{2}{*}{ Point } & \multicolumn{2}{|c|}{ Koordinat } & \multirow[b]{2}{*}{$f_{0}$} & \multirow[b]{2}{*}{ Jenis Tanah } \\
\hline & $\mathbf{X}$ & $\mathbf{Y}$ & & \\
\hline A 01 & 122.5771 & 3.988983 & 6.57 & Gravel \\
\hline A 02 & 122.5851 & 3.987083 & 5.1 & Alluvial Sandy Gravel \\
\hline A 03 & 122.5535 & 4.005444 & 1.4 & Alluvial \\
\hline A 04 & 122.5611 & 4.004333 & 1.4 & Alluvial \\
\hline A 05 & 122.5707 & 4.005125 & 4.694 & Alluvial Sandy Gravel \\
\hline A 06 & 122.5668 & 4.012608 & 2.90228 & Alluvial Loam \\
\hline A 07 & 122.5654 & 4.002317 & 1.32791 & Alluvial \\
\hline A 08 & 122.5792 & 3.996608 & 1.35292 & Alluvial \\
\hline A 09 & 122.5533 & 4.001556 & 5.36938 & Alluvial Sandy Gravel \\
\hline A 10 & 122.5553 & 4.014258 & 4.53878 & Alluvial Sandy Gravel \\
\hline A 11 & 122.5608 & 4.012653 & 3.86561 & Alluvial Loam \\
\hline A 12 & 122.5858 & 3.994472 & 1.3663 & Alluvial \\
\hline
\end{tabular}




\begin{tabular}{llllc}
\hline A 13 & 122.5791 & 4.003803 & 4.15114 & Alluvial Sandy Gravel \\
\hline A 14 & 122.5773 & 4.009936 & 3.17799 & Alluvial Loam \\
\hline A 15 & 122.5839 & 4.007431 & 1.26478 & Alluvial \\
\hline A 16 & 122.5851 & 4.001492 & 0.81501 & Lumpur \\
\hline A 17 & 122.5472 & 4.014097 & 2.41924 & Alluvial Top Soil \\
\hline A 18 & 122.5474 & 4.000603 & 1.28868 & Alluvial \\
\hline A 19 & 122.5564 & 3.996606 & 1.73336 & Alluvial \\
\hline A 20 & 122.5712 & 3.991633 & 0.65604 & Lumpur \\
\hline
\end{tabular}

Sumber: Hasil observasi dan wawancara di BMKG 2018

Tabel 4.2 adalah tabel hasil pengukuran lapangan.Selanjutnya informasi dari tabel 4.2 dibuatkan peta sebaran titik pengukuran. Adapun peta titik sebaran pengukuran dapat dilihat pada gambar di bawah ini.

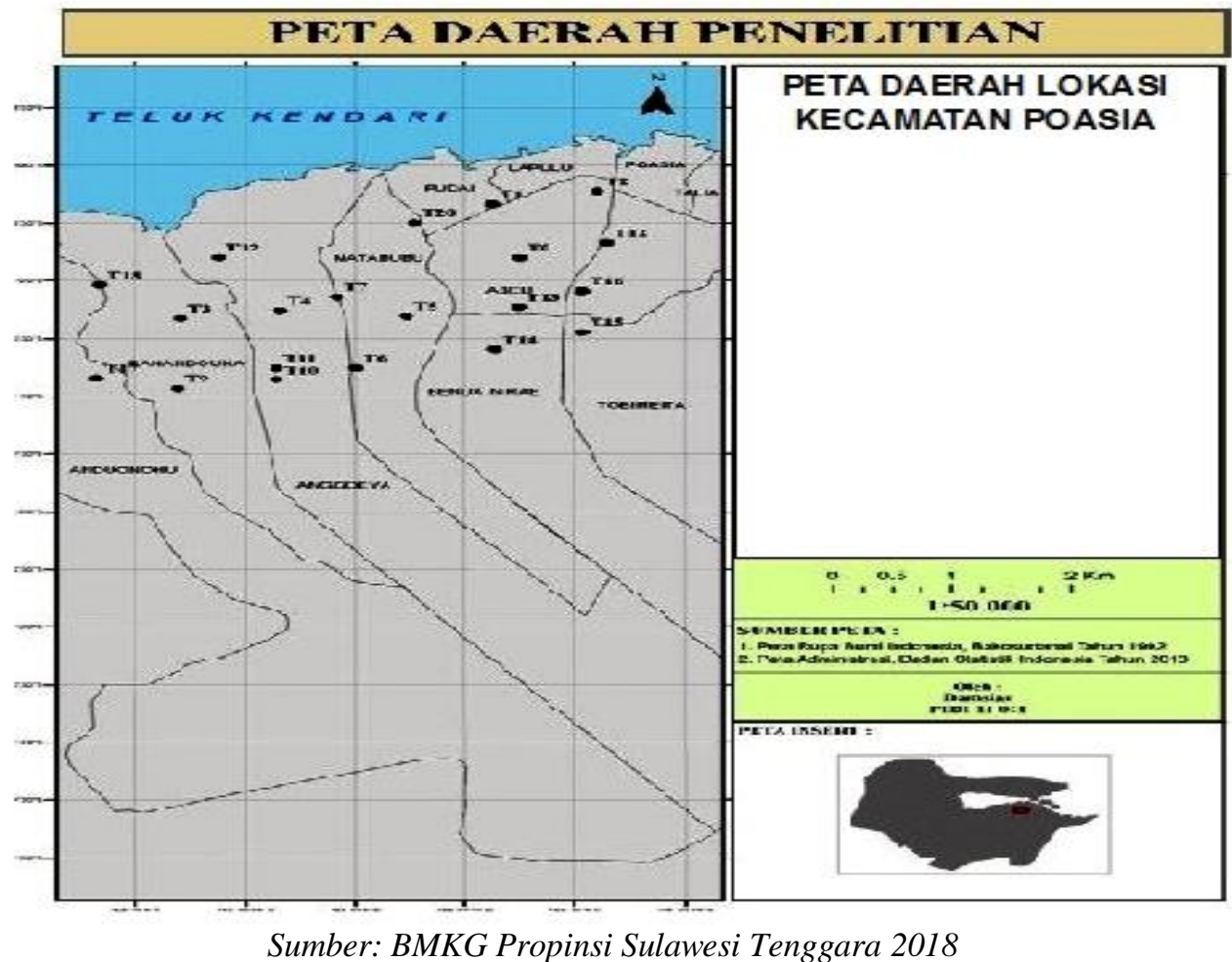

Gambar 4.1 adalah peta daerah titik pengukuran yang berisi informasi koordinat wilayah titik pengukuran dan jenis tanah $\left(f_{0}\right)$. Adapun penjabaran dari hasil pengukuran lapangan berdasarkan titik pengukuranya bahwasanya untuk titik
pengukuranA 01 s/d A 20, Dari tiaptiap titik pengukuran kita dapat membuat tabel presentase berdasarkan Tipe klasifikasi tanah. Adapun tabel presentasenya dapat dilihat di bawah ini: 
Tabel 4.3. Presentase Tipe Pengukuran

\begin{tabular}{llcc}
\hline Kecamatan & Tipe Klasifikasi & Jumlah titik & Persentase(\%) \\
\hline \multirow{3}{*}{ Poasia } & TIPE I \& II & 11 & 55 \\
\cline { 2 - 4 } & TIPE III & 3 & 15 \\
\cline { 2 - 4 } & TIPE IV & 6 & 30 \\
\hline \multicolumn{2}{c}{ Jumlah } & $\mathbf{2 0}$ & $\mathbf{1 0 0 \%}$ \\
\hline
\end{tabular}

Sumber: Data Primer Di Olah 2018

Jadi berdasarkan persentase hasil pengukuran lapangan diperoleh $55 \%$ terdiri atas jenis tanah alluvial berlumpur, $15 \%$ terdiri atas alluvial dengan jenis loam dan $30 \%$ terdiri atas gravel dan sandy gravel. Dapat dikatakan bahwa dominasi tanah alluvial berlumpur di Kecamatan Poasia. Ini disebabkan kecamatan ini terletak dekat dengan daerah aliran sungai Wanggu dan karena dominasi tanah alluvial menyebabkan adanya genangan air yang menyebabkan banjir dan jenis tanah ini sangat cocok untuk bertani. Adapun untuk melihat sebaran jenis tanah di Kecamatan Poasia dapat dilihat pada gambar 3.2

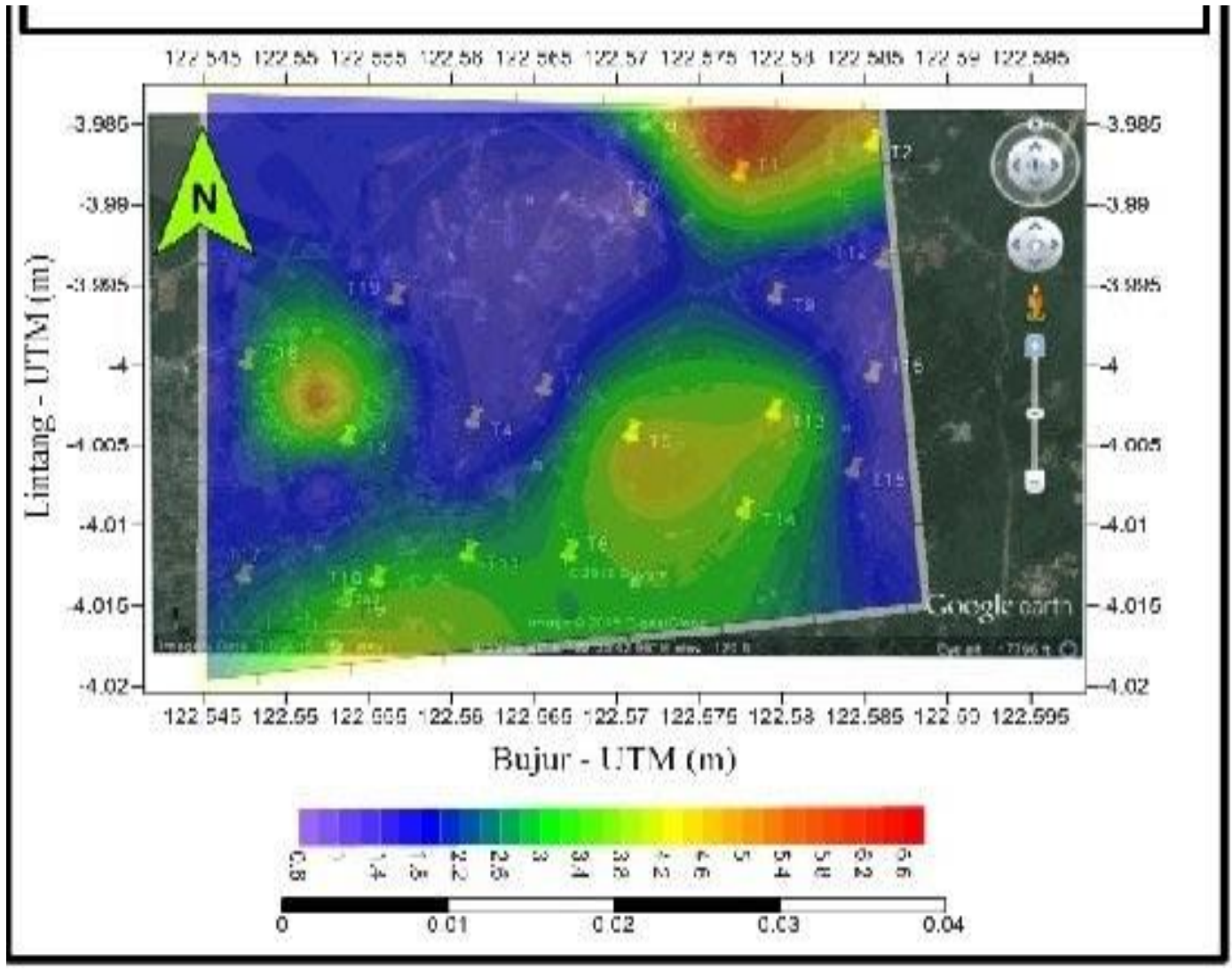

Gambar 4.2 Peta Sebaran Jenis Tanah

Keterangan Warna Gambar:

\begin{tabular}{lll}
\hline 1. & Ungu - Biru & : Lumpur dan Alluvial \\
\hline 2. & Hijau - Kuning & : Alluvial Loam dan Alluvial Top Soil \\
\hline 3. & Jingga - Merah & : Alluvial Sandy Gravel dan Gravel \\
\hline \multicolumn{2}{c}{ Sumber: Hasil Analisis Penelitan 2018 }
\end{tabular}


Berdasarkan Gambar 4.2 memperlihatkan nilai frekuensi dominan yang diperoleh cukup bervariasi. Variasi tersebut dapat ditunjukan dengan perubahan pola warna, dimana warna ungu - biru berkisar antara $0,6-2,2 \mathrm{~Hz}$, warna hijau - kuning berkisar antara 2,4-4,2 $\mathrm{Hz}$ sedangkan warna jingga - merah berkisar antara 4,4 - 6,6 Hz. Secara umum klasifikasi tingkat frekuensi dominan yang diperoleh masih dikategorikan rendah atau $\leq 7 \mathrm{~Hz}$. Sebaran frekuensi dominan di wilayah Kelurahan Anduonohu sebanyak 20 titik pengukuran dapat dilihat pada Gambar 4.2

Penting diketahui bahwa saat peneliti dalam mengambil data mentah dari BAPPEDA dan berdiskusi langsung dengan salah satu pegawai disana diperoleh informasi bahwa data dari lembaga ini kurang akurat. Perlu diketahui infomasi peta jenis tanah yang disajikan dari instansi Badan Perencanaan Pembangunan Daerah (BAPPEDA) hanya memetakan sebaran jenis tanah berdasarkan jenis yang dominan pada wilayah kota kendari dengan persentase tidak diketahui. Jadi secara ilmiah penyajian informasi jenis tanah yang ada pada instansi tersebut tidak akurat.

\section{KESIMPULAN}

Berdasarkan hasil penelitian dan pembahasan yang telah di paparkan diatas maka peneliti berkesimpulan sebagai berikut :

1. Gambaran jenis tanah di Keluarahan AnduonohuKecamatan Poasiaterdiri atas 5 (lima) jenis, yaitu alluvial, lumpur, alluvial sandy gravel, alluvial loam dan alluvial top soil.

2. Persebaran jenis tanah di Kelurahan Anduonohu Kecamatan Poasia di dominasi oleh jenis alluvial dan berlumpur $55 \%, 15 \%$ terdiri atas alluvial dengan jenis loam dan $30 \%$ terdiri atas gravel dan sandy gravel.

\section{DAFTAR PUSTAKA}

Agus S, Muntohar. 2010. Mikrozonasi Potensi Likuifaksi dan Penurunan Tanah Akibat Gempa Bumi. Yogyakarta, Universitas Muhammadiyah Yogyakarta

Daryono. 2009. Pengkajian Local Site Effect di Graben Bantul Menggunakan Indeks Kerentanan Seismik Berdasarkan Pengukuran Mikrotremor. Jurnal Kebencanaan Indonesia Vol. 2, No.1 Mei 2009. Hal.13. Yogyakarta: PSBA.

Prahasta, Eddy. 2002. Konsep-konsep Dasar Sistem Informasi Geografis. Bandung: Informatika

Prapto Suharsono, 1989, Sistem Informasi Geografi (SIG) dan Sistem Informasi Lahan (LIS) dan Peranannya di dalam Menunjang Pembangunan. Yogyakarta: Fakultas Geografi UGM.

Suharto Paul. 1989. Peranan Sistem Informasi Geografi (GIS) dalam Pengelolaan Sumberdaya Hutan di Indonesia, Majalah Forum.

Sulkarnain, 2008. Kecamatan Poasia dalam Angka 2014. Kendari, UHO. 
Jurnal Penelitian Pendidikan Geografi Volume 4 No. 1 Januari 2019

Tommy, A., 2012. Analisis Struktur Lapisan Tanah Berdasarkan Ketebalan Sedimen Menggunakan Mikrotremor Dengan Metode Horizontal To Vertical Spectral Ratio (HVSR), Skripsi S-1, Yogyakarta: Universitas Islam Negeri Sunan Kalijaga. 